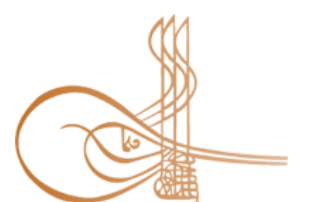

www.turkishstudies.net/social
Turkish Studies - Social Sciences

eISSN: 2667-5617

Research Article / Araștırma Makalesi

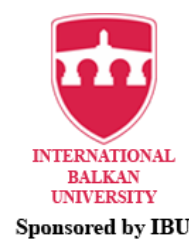

Sponsored by IBU

\title{
Serbest Zaman Fayda İle Mutluluk Arasındaki İlişki: Spor Bilimleri Fakülteleri Öğrencileri
}

The Relationship between Leisure Benefit and Happiness: Students of the Faculty of Sports Science

\author{
Emrah Serdar*
}

\begin{abstract}
This study aims to determine the differences between the leisure benefit and happiness levels of students studying in the faculty of sports sciences according to particular socio-demographic characteristics and to measure the predictive power of participants' leisure benefit levels on their happiness. A total of 328 participants, including 182 male and 146 female, studying in different sports sciences faculties selected by the convenience sampling method, constitute the study sample. In addition to the Personal Information Form, the "Oxford Happiness Scale-Short Form" developed by Hills and Argyle (2002) and adapted to Turkish by Doğan and Çötok (2011) and the "Leisure Benefit Scale" developed by Ho (2008) and adapted to Turkish by Akgül et al. (2018) were used as data collection instruments in the research. Descriptive statistics, independent t-test, ANOVA, MANOVA, and regression analyzes were adopted in the analysis of the data. Independent t-test results show that there is no significant difference between individuals' happiness levels and gender. According to ANOVA results, there are meaningful differences between the participants' welfare and happiness levels, while no significant difference was found in weekly leisure. Also, MANOVA results indicate that the main effect of individuals 'gender and welfare status on leisure benefit levels is insignificant, and there is no difference between sub-dimensions. However, the main effect of participants' weekly leisure periods on benefit levels is significant, and it has been observed that individuals with a leisure time of 16 hours or more per week score higher in "social benefit" sub-dimension. The results of the regression analysis show that leisure benefits are a significant predictor of happiness. Consequently, it was concluded that socio-demographic characteristics play a role in individuals' leisure benefit and happiness levels, and the benefits of participants in leisure were an essential factor in their happiness.
\end{abstract}

Structured Abstract: This study aims to describe the differences between leisure benefits and happiness levels of the students who study at the faculty of sports sciences according to their socio-demographic features and to evaluate the predictive power of the participants' leisure benefits on their happiness levels. Hence, the research group which was selected by convenience sampling method included 328 students from different sports science faculties in Turkey. Of the total 328 participants, 182 were male (mean age $=21: 07 \pm 2.82)$ and 146 were female (mean ${ }_{\text {age }}=20.89 \pm 2.69$ ). While the participants had leisure time of "16 Hours and Over" weekly, $63.4 \%$ of them were found to possess "normal welfare status." Within the scope of the research, the data collection tool consists of three parts. In the first part, a personal information form involving questions such as gender, age, department, grade, welfare status, and weekly leisure time was used to collect information about the individuals in the study. In the second part, the "Oxford Happiness Scale-Short Form" developed by Hills and Argyle (2002) and adapted to Turkish by Doğan and Çötok (2011) was used to specify the happiness

\footnotetext{
* Arș. Gör. Dr. İstanbul Üniversitesi - Cerrahpaşa, Spor Bilimleri Fakültesi, Spor Yöneticiliği Bölümü PhD, Research Assistant, Istanbul University - Cerrahpasa, Faculty of Sports Science, Department of Sports Management ORCID 0000-0003-2438-6748

serdar-emrah@hotmail.com

Cite as/ Atıf: Serdar, E. (2020). Serbest zaman fayda ile mutluluk arasındaki ilişki: spor bilimleri fakültesi öğrencileri.

Turkish Studies - Social, 15(5), 2711-2721. https://dx.doi.org/10.47356/TurkishStudies.44273

Received/Geliş: 16 June/Haziran 2020

Accepted/Kabul: 20 August/Ağustos 2020

Checked by plagiarism software

Copyright (C) INTAC LTD, Turkey 
levels of individuals. The scale has seven items and one sub-dimension, and the reliability coefficient has been measured as 0.85 . In our study, the scale reliability coefficient was determined as 0.92 . The items in the scale are scored as (1) Strongly Disagree at all, (5) Strongly Agree. In the last section, the "Leisure Benefit Scale" developed by Ho (2008) and adapted to Turkish by Akgül et al. (2018) was applied to determine the benefit levels of participants from their leisure activities. The scale consists of three sub-dimensions: "Physical Benefit" (7 Items), "Psychological Benefit" (8 Items), and "Social Benefit" (9 Items). The reliability coefficient of the scale was determined as 0.83 , while internal consistency for the sub-dimensions were 0.81 for physical benefit, 0.80 for the psychological benefit, and 0.86 for social benefit. In the current study, it is 0.91 for the physical benefit sub-dimension, 0.84 for the psychological benefit, and 0.90 for the social benefit. Data collection, necessary permissions and consent were acquired before data collection. The participant students from different sports faculties completed the online tools voluntarily. The researcher eliminated the incomplete or incorrectly filled surveys, and only the valid and reliable ones were included in the dataset. The study received the consent of the Ethics Committee in Istanbul Univesity-Cerrahpaşa Social and Human Sciences Research Grant Group on 02.06.2020 (71886). SPSS 20.0 software package was used to analyze the data. The researcher also applied to frequency and percentage method to measure the distribution for the participants' personal information. Skewness and kurtosis values were examined to determine whether the data was of a normal distribution, and it was found that the data showed a normal distribution. In this sense, independent $t$ test, ANOVA, single-factor MANOVA, and regression analysis were applied. Finally, Cronbach Alpha coefficients were calculated to determine the reliability of the scales. Considering the average scores of the participants, it was 3.12 for OHS. It was determined that the highest mean at the LBS sub-dimensions was in the "Physical Benefit" sub-dimension (3.96), and the lowest was in the "Social Benefit" sub-dimension (3.84). When the analysis results are analyzed according to the participants' gender, OHS scores of the participants do not show a significant difference in terms of gender $(t=1.866 ; p>0.05)$. The results of MANOVA analysis revealed that the main effect of participants' gender on sub-dimensions of LBS was not significant, and there was no statistically significant difference between the sub-dimensions $\left[\lambda=0.985, \mathrm{~F}_{(3,324)}=1.690 ; \mathrm{p}<0.05\right]$. To the analysis results based on welfare states, there was a significant difference in participants' OHS scores according to their welfare status $(\mathrm{F}=6.005 ; \mathrm{p}<0.05)$. It was concluded that the participants with high welfare status had higher happiness levels. The results of MANOVA analysis revealed that the main effect of the participants' welfare status on the sub-dimensions of LBS was not significant, and there was no statistically significant difference between the sub-dimensions $\left[\lambda=0.986, \mathrm{~F}_{(6,646)}=0.782 ; \mathrm{p}<0.05\right]$. When the analysis results were analyzed according to the weekly leisure periods of the research participants, OHS scores did not differ significantly from their weekly leisure periods $(\mathrm{F}=2.165 ; \mathrm{p}>0.05)$. The results of MANOVA analysis indicate that the main effect of the participants' weekly leisure periods on the sub-dimensions of LBS is significant $\left[\lambda=0.929, \mathrm{~F}_{(9,783)}=2.670 ; \mathrm{p}<0.05\right]$ and it was determined that there was a meaningful difference only in the "Social Benefit" sub-dimension $\left(\mathrm{F}_{(3,324)}=3.385 ; \mathrm{p}<0.05\right)$. The participants' average scores with a leisure period of 16 hours or more per week were higher than those of other individuals. According to the results of the regression analysis, it was found that individuals' leisure benefit levels were a significant predictor of their happiness levels $\left(\mathrm{R}=0.183 ; \mathrm{R}^{2}=.033 ; \mathrm{F}(1,326)=11.291, \mathrm{p}<0.05\right)$. Hence, there is a positive and lowlevel relationship $(\mathrm{R}=0.183)$ between the leisure benefit and happiness levels of the participants, and the leisure time benefit levels explain $33 \%$ of the total variance on happiness levels. Consequently, it was concluded that leisure time benefit and happiness levels differ according to the socio-demographic characteristics of individuals and that the benefits of participants in leisure were important. It has been determined that males have higher levels of happiness than females and physically and psychologically take advantage of leisure activities. It is understood that individuals with good welfare have higher levels of happiness. However, it was observed that individuals' financial well-being was not effective in their leisure benefit levels. Besides, as individuals' leisure improves, their happiness level increases, and they gain more social benefits from leisure. It is concluded that individuals' leisure benefits have a significant impact on their happiness.

Keywords: Sport Sciences, Sport Science Students, Leisure, Leisure Benefit, Happiness

Öz: Bu araştırmada, spor bilimleri fakültelerinde okuyan öğrencilerin sosyo-demografik özelliklerine göre serbest zaman fayda düzeyleri ile mutluluk düzeyleri arasındaki farklılıkları ve katılımcıların serbest zaman fayda düzeylerinin mutluluk düzeylerini yordama gücünün belirlenmesi amaçlanmaktadır. Araştırmanın örneklemini kolayda örneklemi yöntemi ile seçilen farklı spor bilimleri fakültelerinde öğrenim gören 182 erkek 
ve 146 kadın üzere toplamda 328 kişi oluşturmaktadır. Çalışmada veri toplama aracı olarak, Kişisel Bilgi Formu, Hills ve Argyle (2002) tarafindan geliştirilen, Doğan ve Çötok (2011) tarafından Türkçe'ye uyarlanan "Oxford Mutluluk Ölçeği Kısa Formu" ile Ho (2008) tarafından geliştirilen, Akgül vd. (2018) tarafından Türkçe'ye uyarlanan "Rekreasyon Fayda Ölçeği” kullanılmıştır. Verilerin değerlendirilmesinde ise betimsel istatistikler, bağımsız t-tesi, ANOVA, MANOVA ve regresyon analizleri kullanılmıştır. Bağımsız t-Tesi sonuçları; bireylerin cinsiyetlerine göre mutluluk düzeyleri arasında farklılık olmadığı, ANOVA sonuçları; katılımcıların refah durumlarına göre mutluluk düzeyleri arasında anlamlı farklılık tespit edilirken, haftalık serbest zaman sürelerine göre ise anlamlı farklılık saptanmamıştır. MANOVA sonuçları; bireylerin cinsiyetleri ve refah durumlarının serbest zaman fayda düzeyleri üzerindeki ana etkisinin anlamlı olmadığı gibi alt boyutlar düzeyinde de farklılık olmadığı, ancak katılımcıların haftalık serbest zaman sürelerinin serbest zaman fayda düzeyleri üzerindeki temel etkisinin anlamlı olduğunu ve alt boyutlar arasında "Sosyal fayda" boyutunda haftalık 16 saat ve üzeri serbest zaman süresine sahip bireylerin daha yüksek puan aldıkları gözlenmiştir. Regresyon analizi sonucunda ise; serbest zamanda elde edilen faydaların mutluluğun anlamlı bir yordayıcısı olduğu tespit edilmiştir. Sonuç olarak bireylerin sosyo-demografik özelliklerine göre serbest zaman fayda düzeyleri ile mutluluk düzeylerinin farklılık gösterdiği ve katılımcıların serbest zamanda elde ettikleri faydaların mutlulukları üzerinde önemli bir etmen olduğu sonucuna varılmıştır.

Anahtar Kelimeler: Spor Bilimleri, Spor Bilimleri Öğrencileri, Serbest Zaman, Serbest Zaman Fayda, Mutluluk

\section{Giriş}

Gelişen teknoloji ve değişen yaşam koşulları nedeniyle serbest zamanın toplumsal yapıdaki rolü son derece önemli bir hale gelmiştir (Henderson, 2010; Serdar vd., 2018). Serbest zaman kavramı, başta fiziksel aktivite olmak üzere turizm, sanatsal ve kültürel aktiviteleri içeren çok geniş bir terim olup (Gürbüz, 2017; Doğan vd., 2019) bireylerin bu zaman diliminde zevk almalarını, mutlu olmalarını ve kendilerini ifade etmeleri için en iyi fırsatları sunmaktadır (Gümüşgül, 2019). Bu nedenle, olumlu bir biçimde değerlendirilen serbest zamanlar insanların yaşamlarına da birçok fayda sağlamaktadır (Eccles, 2005; Güngörmüş vd., 2017; Kim vd., 2018; Sarol vd., 2020).

Serbest zaman fayda kavramı bireylerin serbest zaman aktivitelerine katılımları sırasında amaçlarına ulaşıp ulaşmadıklarını veya çeşitli faydalar elde edip etmediklerine göre değerlendirilen deneyimsel algılar şeklinde tanımlanmaktadır (Kuo, 2013). Bu noktadan hareketle, alanyazın incelediğinde serbest zaman faydalarının farklı şekillerde sınıflandırıldığını görülmektedir. Bright (2000) serbest zaman aktivitelerin bireylerin yaşamlarına psikososyal, fiziksel, sosyal, ekonomik ve çevresel yönden faydalar sağladığını belirtmiştir. Lee ve Lin (2011) serbest zaman aktivitelerine katılan bireylerin sıklıkla fizyolojik, sosyal, rahatlama, eğitim, estetik ve psikolojik yönden faydalar elde ettiğini belirtmiştir. Hung (2012) ise serbest zaman faydalarını genel olarak fiziksel, psikolojik ve sosyal olmak üzere üç başlık altında sınıflandırmaktadır. Fiziksel Faydalar: Bireyler serbest zaman aktivitelerine katılımları sonucunda zinde ve sağlıklı olma, kilo kontrolü ve iyi olma hali gibi faydalar elde etmektedirler (Yurcu vd., 2018). Psikolojik Faydalar: Bireylerin yaşam baskısından kurtulma, duygusal, zihinsel ve bedensel gevşeme, yaratıcı düşünme ve yaşamdan zevk alma olarak açıklanmaktadır (Eskiler vd., 2019). Sosyal Faydalar ise: Sosyal hayattan doyum almak, toplumsal birliği ve uyumu teşvik etmek, arkadaşlık ve aile sevgisini geliştirmek, bireylerin sosyal statülerini yükseltmek ve bireylerin yaşam kalitelerinin iyileştirilmesine katkı sağlamaktadır (Huang vd., 2014). Bireyler serbest zaman aktivitelerine tek başına katıldıklarında sadece fizyolojik ve psikolojik faydalar elde ederken, organize olmuş bir grupla ya da toplulukla aktiviteye katıldıklarında ise, serbest zamanlardan daha çok sosyal yönden fayda elde etmektedirler (Yeh vd., 2017; Chang vd., 2018). Bu görüşe paralel olarak, Coleman (1993) ise serbest zaman aktiviteleri sayesinde bireylerin, arkadaşları, komşuları ve aile üyeleri ile arasındaki kişilerarası etkileşimin, psikolojik sağlığın sağlanması ve sürdürülmesi ile yaşamdaki mutluluk algısının artmasına yardımcı olabileceğini belirtmiştir (Chang vd., 2018). Yine, insanların serbest zaman aktivitelerinden memnun olduklarında mutlu hissedeceklerini ifade edilmiştir (Spiers ve Walker, 2008; Liu ve Da, 2020). Tinsley ve Tinsley 
(1986) ise, serbest zaman aktivitelerine kat1lım ile serbest zamandan elde edilen faydaların toplumların mutluluk düzeylerinin artmasında önemli bir etken olabileceğini belirtmişlerdir (Lee vd., 2016). Bu nedenle, serbest zaman aktiviteleri önemli bir mutluluk kaynağı olarak açıklanmaktadır (Kaya, 2016). Mutluluk kavramı, günlük yaşamda sık kullanımı nedeniyle görünüşte kavramsal olarak açıklanması kolay olsa da, aslında çok kapsamlı bir kavramdır (Demirel, 2019). Spiers ve Walker (2008) ise, hem bilişsel hem de duygusal yönleri ile incelenebilen mutluluk kavramını iyi bir yaşam anlamına geldiğini ifade etmişlerdir (Wei vd., 2015). Genel olarak insanların olumlu ruh halinde olma durumu olarak açıklanan mutluluk kavramı (Camfield ve Skevington, 2008; Arvas, 2017) olumlu hislerin, olumsuz duygulara oranla daha fazla yaşanması, yaşamdan yüksek seviyede memnuniyet duyma olarak ifade edilmektedir (Sapmaz ve Doğan, 2012; Sevin ve Şen, 2019).

Literatürde serbest zaman ile mutluluk kavramlarının ele alınarak yapılan çalışmalar incelendiğinde; serbest zaman ilgilenimi ve mutluluk (Aydın, 2016; Demirel, 2019), serbest zaman doyumu ve mutluluk (Spiers ve Walker, 2008; Kaya, 2016; Serdar vd., 2018; Dikici, 2020), serbest zaman fayda ve mutluluk (Chen vd., 2013; Doğan, 2018; Yalçınkaya, 2019), serbest zaman tutumu ve mutluluk (Durmaz, 2020) arasında olumlu bir ilişki olduğunu destekleyen çalışmalara rastlamak mümkündür. Serbest zaman aktiviteleri sosyalleşmede önemli bir faktör olarak kabul edilmektedir. Karaca ve Lapa (2016) ise, üniversite dönemlerinin insanların yaşamları üzerinde önemli bir etkiye sahip olduğunu ifade etmişlerdir. Bu noktadan hareketle, üniversitede öğrenim gören bireylerin serbest zamanlarını olumlu bir şekilde değerlendirmeleri ve serbest zaman aktivitelerine katılmaları, onların eğitim süreçlerini olumlu yönde etkileyeceği gibi, genel olarak fiziksel, psikolojik ve sosyal yönde de fayda elde etmelerine katkı sağlayacaktır. Bu doğrultuda çalışmanın amacı spor bilimleri fakültelerinde öğrenim gören öğrencilerin sosyo-demoğrafik özelliklerine göre serbest zaman fayda düzeyleri ile mutluluk düzeyleri arasındaki farklılıklar ile serbest zamanlardan elde ettikleri faydaların mutluluk düzeyleri üzerindeki etkisinin belirlenmesidir.

\section{Yöntem}

Araştırma Model: Araştırmada çalışmanın amacı doğrultusunda tarama modeli kullanılmıştır. Evren hakkında genel bir yargıya varabilmek amacıyla, evrenin tümünü ya da temsil ettiği düşünülen bir örneklem üzerinde çalışma yapılmasına tarama modeli denmektedir (İslamoğlu ve Alnıaçık, 2014). İlişkisel tarama modeli ise, iki veya daha fazla sayıdaki değişkenin birlikte değişim varlığını, yönünü ve şiddetini belirlemeye çalışılması olarak tanımlanmaktadır (Karasar, 2014).

Araştırma Grubu: Araştırmanın çalışma grubunu; Türkiye'de farklı üniversitelerin spor bilimleri fakültelerinde okuyan, kolayda örneklemi yöntemi ile seçilen 182 erkek $\left(\right.$ Ort $\left._{\text {yaş }}=21.07 \pm 2.82\right)$ ve 146 kadın $\left(\right.$ Ort $\left._{\text {yaş }}=20.89 \pm 2.69\right)$ olmak üzere toplamda 328 kişi oluşturmuştur. Araştırmaya katılanların haftalık "16 Saat ve Üzeri” arasında serbest zamana sahip iken, \%63,4’ünün ise refah durumunun "Normal" olduğu tespit edilmiştir.

\section{Veri Toplama Araçları}

Kişisel Bilgi Formu: Çalışmada yer alan katılımcıların; cinsiyet, yaş, bölüm, sınıf, refah durumu ve haftalık serbest zaman süreleri hakkında bilgi almak amacıyla araştırmacı tarafından hazırlanan Kişisel Bilgi Formu kullanılmıştır.

Oxford Mutluluk Ölçeği-Kısa Formu: Bireylerin mutluluk düzeylerini belirlemek için, Hills ve Argyle (2002) tarafindan geliştirilen, Doğan ve Çötok (2011) tarafindan Türkçe'ye uyarlanan "Oxford Mutluluk Ölçeği Kısa Formu" kullanılmıştır. Ölçek 7 madde ve tek alt boyutlu olup, güvenirlik kat sayısı 0.85 olarak tespit edilmiştir. Ölçekte yer alan maddeler (1) Hiç Katılmıyorum, (5) Tamamen Katılıyorum şeklinde puanlanmaktadır.

Rekreasyon Fayda Ölçeği: Bireylerin serbest zaman aktivitelerinden elde ettikleri faydayı belirlemek amacıyla, Ho (2008) tarafından geliştirilen, Akgül vd., (2018) tarafından Türkçe'ye 
uyarlanan "Rekreasyon Fayda Ölçeği” kullanılmıştır. Ölçeğin "Fiziksel Fayda" (7 Madde), "Psikolojik Fayda" ( 8 Madde) ve "Sosyal Fayda" (9 Madde) olmak üzere üç alt boyut ve 24 maddeden oluşmaktadır. Ölçeğin güvenirlik kat sayısı 0.83 olarak tespit edilirken, alt boyutlar için iç tutarlıl1k katsayıları fiziksel fayda alt boyutu için 0.81 , psikolojik fayda alt boyutu için 0.80 , sosyal fayda alt boyutu için ise 0.86 olarak hesaplanmıştır. Ölçekte yer alan maddeler (1) Hiç Katılmıyorum, (5) Tamamen Katılıyorum şeklinde puanlanmaktadır.

Veri Toplama Süreci: Çalışma kapsamında kullanılan veri toplama araçlarının uygulanması, gerekli izinlerin alınmasından sonra gerçekleştirilmiştir. Veri toplama araçları, online platformda farklı spor bilimleri fakültelerinde öğrenim gören öğrenciler tarafından gönüllü olarak doldurulmuştur. Verilen cevaplar araştırmacı tarafindan kontrol edilerek eksik veya hatalı olanlar çalışma dişında tutulmuş olup, geçerli ve kabul edilebilir nitelikte olanlar ise, değerlendirilmek üzere araştırmaya dahil edilmiştir. Ayrıca, bu çalışma İstanbul Üniversitesi-Cerrahpaşa Sosyal ve Beşeri Bilimler Araştırmaları Etik Kurul başkanlığının 02.06.2020 tarihli 71886 sayılı kararı sonucunda çalışmanın etik açıdan uygun olduğuna oybirliği ile karar verilmiştir.

Verilerin Analizi: Verilerin analizinde SPSS 20.0 paket programı kullanılmıştır. Katılımcıların kişisel bilgilerine yönelik dağılımları belirmek için yüzde ve frekans yönteminden faydalanılmıştır. Verilerin normal dağılım gösterip göstermediğini belirlemek amacıyla çarpıklık ve basıklık değerleri incelenmiş olup, verilerin normal dağılım gösterdiği anlaşılmıştır. Bu bağlamda değişkenlerin analizinde; Bağımsız t Testi, ANOVA, tek faktörlü MANOVA ve Regresyon analizleri kullanılmıştır. Son olarak ise, ölçeklerin güvenirliliklerini tespit etmek için Cronbach Alpha katsayıları hesaplanmıştır. Oxford Mutluluk Ölçeğinin güvenirlik kat sayısı 0.92 olarak tespit edilirken, Rekreasyonda Fayda Ölçeğinin ise, iç tutarlılık katsayılarının 0.84 ile 0.91 arasında değiştiği saptanmıştır.

\section{Bulgular}

Tablo 1: Ölçek Puanlarının Dağılımı

\begin{tabular}{cccccccc}
\hline & Ölçek Alt Boyutları & $\begin{array}{c}\text { Madde } \\
\text { Sayısı }\end{array}$ & N & Ort. & Ss. & Çar. & Bas. \\
\hline OMÖ-K & Oxford Mutluluk & 7 & 328 & 3.12 & 0.56 & -.120 & -.287 \\
\hline \multirow{3}{*}{ RFÖ } & Fiziksel Fayda & 7 & 328 & 3.96 & 0.68 & -.718 & 1.019 \\
\cline { 2 - 8 } & Psikolojik Fayda & 8 & 328 & 3.89 & 0.73 & -.552 & .341 \\
\cline { 2 - 8 } & Sosyal Fayda & 9 & 328 & 3.84 & 0.74 & -.768 & .727 \\
\hline
\end{tabular}

Tablo 1'de araştırmada yer alan katılımcıların ölçek alt boyutlarından aldıkları ortalama puanlar incelendiğinde; OMÖ'nin ortalama puanı (3.12) olarak tespit edilmiştir. RFÖ'nin alt boyutlar düzeyinde en yüksek ortalamanın "Fiziksel Fayda" (3.96) alt boyutunda olduğu, en düşük ortalamanın ise, "Sosyal Fayda" (3.84) alt boyutunda olduğu saptanmıştır.

Tablo 2: OMÖ-K ile RFÖ Puanlarının Katılımcıların Cinsiyetlerine Göre Analiz Sonuçları Ölçekler

\begin{tabular}{lllll} 
& Ort. & Ss. & Ort. & Ss. \\
\hline OMÖ-K & 3.17 & 0.57 & 3.05 & 0.54 \\
\hline RFÖ & & & & \\
$\quad$ Fiziksel Fayda & 4.00 & 0.69 & 3.91 & 0.65 \\
$\quad$ Psikolojik Fayda & 3.93 & 0.72 & 3.84 & 0.74 \\
$\quad$ Sosyal Fayda & 3.83 & 0.75 & 3.84 & 0.72 \\
\hline
\end{tabular}

Tablo 2'de araştırmada yer alan katılımcıların cinsiyetlerine göre analiz sonuçları verilmiştir. Bağımsız t-Testi sonuçlarına göre; bireylerin OMÖ-K puanları cinsiyetlerine göre anlamlı bir 
farklılık bulunmamaktadır $(\mathrm{t}=1.866 ; \mathrm{p}>0.05)$. MANOVA analizi sonuçları, katılımcıların cinsiyetlerinin RFÖ'nin alt boyutları üzerindeki ana etkisinin anlamlı olmadığı ve alt boyutlar arasında da anlamlı farklılık olmadığ 1 tespit edilmiştir $\left[\lambda=0.985, \mathrm{~F}_{(3,324)}=1.690 ; \mathrm{p}>0.05\right]$.

Tablo 3: OMÖ-K ile RFÖ Puanlarının Katılımcıların Refah Durumlarına Göre Analiz Sonuçları

\begin{tabular}{|c|c|c|c|c|c|c|}
\hline \multirow{2}{*}{ Ölçekler } & \multicolumn{2}{|c|}{ Kötü $(N=50)$} & \multicolumn{2}{|c|}{ Normal $(N=208)$} & \multicolumn{2}{|c|}{$\dot{I y i}(N=70)$} \\
\hline & Ort. & Ss. & Ort. & Ss. & Ort. & Ss. \\
\hline OMÖ-K & 2.91 & 0.56 & 3.12 & 0.56 & 3.27 & 0.53 \\
\hline \multicolumn{7}{|l|}{$\overline{\text { RFÖ }}$} \\
\hline Fiziksel Fayda & 3.94 & 0.75 & 3.91 & 0.70 & 4.10 & 0.53 \\
\hline Psikolojik Fayda & 3.92 & 0.78 & 3.84 & 0.74 & 4.01 & 0.66 \\
\hline Sosyal Fayda & 3.89 & 0.70 & 3.79 & 0.79 & 3.94 & 0.59 \\
\hline
\end{tabular}

Tablo 3'de araştırmada yer alan katılımcıların refah durumlarına göre analiz sonuçları verilmiştir. ANOVA sonuçlarına göre; bireylerin OMÖ-K puanları refah durumlarına göre anlamlı bir farklılık saptanmıştır $(\mathrm{F}=6.005 ; \mathrm{p}<0.05)$. Refah düzeyi iyi olan bireylerin mutluluk düzeyleri daha yüksek olduğu sonucuna ulaşılmıştır. MANOVA analizi sonuçları, katılımcıların refah durumlarının RFÖ'nin alt boyutları üzerindeki ana etkisinin anlamlı olmadığı ve alt boyutlar arasında da farklılık bulunamamıştır $\left[\lambda=0.986, \mathrm{~F}_{(6,646)}=0.782 ; \mathrm{p}>0.05\right]$.

Tablo 4: OMÖ-K ile RFÖ Puanlarının Katılımcıların Haftalık Serbest Zaman Sürelerine Göre Analiz Sonuçları

\begin{tabular}{|c|c|c|c|c|c|c|c|c|}
\hline \multirow{2}{*}{ Ölçekler } & \multicolumn{2}{|c|}{$\begin{array}{l}\text { 1-5 Saat } \\
(N=63)\end{array}$} & \multicolumn{2}{|c|}{$\begin{array}{l}\text { 6-10 Saat } \\
(N=89)\end{array}$} & \multicolumn{2}{|c|}{$\begin{array}{l}\text { 11-15 Saat } \\
(N=80)\end{array}$} & \multicolumn{2}{|c|}{$\begin{array}{c}16 \text { Saat ve } \ddot{U} z e r \\
(N=96)\end{array}$} \\
\hline & Ort. & Ss. & Ort. & Ss. & Ort. & Ss. & Ort. & Ss. \\
\hline OMÖ-K & 3.10 & 0.58 & 3.09 & 0.59 & 3.03 & 0.54 & 3.23 & 0.52 \\
\hline \multicolumn{9}{|l|}{ RFÖ } \\
\hline Fiziksel Fayda & 3.83 & 0.75 & 3.86 & 0.75 & 4.05 & 0.60 & 4.05 & 0.59 \\
\hline Psikolojik Fayda & 3.80 & 0.74 & 3.85 & 0.81 & 3.93 & 0.72 & 3.95 & 0.66 \\
\hline Sosyal Fayda & 3.75 & 0.79 & 3.68 & 0.82 & 3.90 & 0.74 & 3.99 & 0.57 \\
\hline
\end{tabular}

Tablo 4'de araştırmada yer alan katılımcıların haftalık serbest zaman sürelerine göre analiz sonuçları verilmiştir. ANOVA sonuçlarına göre; bireylerin OMÖ-K puanlarına göre haftalık serbest zaman süreleri arasında anlamlı farklılık bulunmamaktadır ( $\mathrm{F}=2.165 ; \mathrm{p}>0.05)$. MANOVA analizi sonuçları, katılımcıların haftalık serbest zaman sürelerinin RFÖ'nin alt boyutları üzerindeki ana etkisinin anlamlı olduğu $\left[\lambda=0.929, \mathrm{~F}_{(9,783)}=2.670 ; \mathrm{p}<0.05\right]$ ve alt boyutlar arasında ise sadece "Sosyal Fayda" boyutunda anlaml farklılık olduğu tespit edilmiştir $\left(\mathrm{F}_{(3,324)}=3.385 ; \mathrm{p}<0.05\right)$. Haftalık 16 saat ve üzeri serbest zaman süresine sahip bireylerin puanları diğer bireylerin puanlarından daha yüksek bulunmuştur.

Tablo 5: RFÖ ile OMÖ-K Regresyon Analizi Sonuçları

\begin{tabular}{lcccc}
\hline & $\mathbf{B}$ & Standart Hata & $\boldsymbol{\beta}$ & P \\
\hline Sabit & 2.525 & .181 & - & $\mathbf{. 0 0 0}$ \\
\hline RFÖ & .154 & .046 & .183 & $\mathbf{. 0 0 1}^{*}$ \\
\hline
\end{tabular}

Tablo 5'de bireylerin serbest zaman fayda düzeyleri ile mutluk düzeylerinin regresyon analizi sonuçları verilmiştir. Analiz sonuçlarına göre; bireylerin serbest zaman fayda düzeylerinin, mutluluk düzeylerinin anlamlı bir yordayıcısı olduğu saptanmıştır $\left(\mathrm{R}=0.183 ; \mathrm{R}^{2}=.033\right.$; $\mathrm{F}(1,326)=11.291, \mathrm{p}<0.05)$. Katılımcıların serbest zaman fayda düzeyleri ile mutluluk düzeyleri arasında pozitif yönde ve düşük seviyede bir ilişki $(\mathrm{R}=0.183)$ olduğu ve serbest zaman fayda düzeyleri, mutluluk düzeyleri üzerindeki toplam varyansın \%33’ünü açıkladığı görülmektedir. 


\section{Tartışma}

$\mathrm{Bu}$ çalışmanın birinci amacı spor bilimleri fakültelerinde okuyan öğrencilerin sosyodemografik özelliklerine göre serbest zamandan elde ettikleri fayda düzeyleri ile mutluluk düzeyleri arasındaki farklılıkların ortaya koyulmasıdır. İkinci amacı ise, katılımcıların serbest zamandan elde ettikleri fayda düzeylerinin mutluluk düzeylerini yordama gücünün belirlenmesidir.

Kadın ve erkeklerin serbest zamandan elde ettikleri fayda düzeyleri incelediğinde, bireylerin cinsiyetlerinin serbest zaman fayda düzeyleri üzerindeki ana etkisinin anlamlı olmadığı ve alt boyutlar arasında farklılık olmadığ 1 saptanmıştır. Bu durum genel olarak, erkek ve kadınların serbest zamandan elde ettikleri fayda düzeylerinin benzer nitelikte olduğu şeklinde yorumlanabilir. Elde edilen bulgular 1şığında alanyazında yapılan çalışmalar incelediğinde ise, Ho (2008) tarafından Tayvan'da lisede öğrenim gören öğrencilerin serbest zaman tutumları ile elde ettikleri fayda düzeylerini inceleyen çalışmada öğrencilerin cinsiyetlerinin serbest zaman faydaları üzerindeki ana etkisinin anlamlı olmadığı ve alt boyutlar arasında farklılık olmadığını saptamışlardır. Yine, Doğan (2018) ile Kocaer (2018) tarafından yapılan çalışmaların sonuçları ile bu çalışmanın sonuçları paralellik gösterirken; Chen vd., (2013) ve Yalçınkaya (2019) tarafından yapılan çalışmaların sonuçları ile örtüşmemektedir. Katılımcıların cinsiyetlerine göre mutluluk düzeyleri incelendiğinde, erkeklerin ortalama puanları kadınlara oranla yüksek olmasına rağmen istatistiksel olarak anlamlı farklılık saptanamamıştır. Konuya ilişkin alanyazında yer alan çalışmalar incelendiğginde, Demirel (2019) tarafindan fitness merkezi katılımcilarının serbest zaman ilgilenimleri ile mutluluk düzeyleri arasındaki ilişkiyi inceleyen çalışmada katılımcıların cinsiyetlerine göre mutluluk düzeylerinde farklılık olmadığı belirtilmiştir. Yine, Aydın, (2016), Akyüz vd., (2018), Serdar vd., (2018) ve Durmaz (2020) tarafından yapılan çalışmaların sonuçları ile bu çalışmanın sonuçları paralellik gösterirken; Wei vd., (2015) tarafından yapılan çalışmada kadınların mutluluk düzeylerinin erkeklerden daha yüksek olduğu belirtilmiştir.

Bireylerin refah durumlarına göre mutluluk düzeyleri incelendiğinde, katımlıcıların refah durumları arasında anlamlı bir farklılık bulunmuştur. Refah durumu iyi olan bireylerin yaşamdan elde ettikleri mutluluk düzeylerinin diğer bireylere oranla daha yüksek olduğu saptanmıştır. $\mathrm{Bu}$ durum, bireylerin refah durumlarının onların mutluluk düzeylerinde önemli bir değişken olduğu şeklinde açıklanabilir. Serdar vd., (2018) tarafından üniversitede öğrenim gören öğrencilerin serbest zaman doyum düzeyleri ile mutluluk düzeyleri arasındaki ilişkiyi inceleyen çalışmada refah durumu iyi olan katılımcıların lehinde anlamlı farklılık saptanmıştır. Elde edilen bulgular neticesinde alanyazında yapılan çalışmalar incelediğinde, Demirel (2019), Yalçınkaya (2019) ve Dikici (2020) tarafından yapılan çalışmaların sonuçları ile paralellik gösterirken; Aydın (2016) tarafından yapılan çalışmada ise, bireylerin gelirlerine göre mutluluk düzeylerinin farklılık göstermediği belirtilmiştir. Bireylerin refah durumlarının serbest zaman fayda düzeyleri üzerindeki ana etkisinin anlamlı olmadığı ve alt boyutlarda farklılık bulunmamıştır. Ho (2008) tarafından yapılan araştırmada öğrencilerin haftalık gelirlerinin serbest zaman fayda düzeyleri üzerindeki ana etkinin anlamlı olmadığ 1 ve alt boyutlarda da farklılık olmadığ tespit edilmiştir.

Bireylerin haftalık serbest zaman sürelerinin serbest zaman fayda düzeyleri üzerindeki temel etkisinin anlamlı olduğu ve alt boyutlar düzeyinde ise, sadece sosyal fayda alt boyutunda anlamlı farklılık saptanmıştır. Haftalık 16 saat ve üzeri serbest zaman süresine sahip bireylerin serbest zamanlardan daha çok sosyal yönden fayda elde ettikleri belirlenmiştir. Bu durum, bireylerin haftalık serbest zaman süreleri arttıkça özellikle serbest zamandan sosyal yönden fayda elde ettikleri şeklinde açıklanabilir. Konuya ilişkin alan yazında yapılan araştırmaları incelendiğinde, Doğan (2018) tarafindan hukuk fakültesinde okuyan öğrencilerin serbest zaman fayda düzeylerinin tüm alt boyutlarında farklılık olduğu tespit edilirken, Kocaer (2018) tarafından yapılan çalışmada ise, bireylerin günlük serbest zaman sürelerine göre serbest zamanda elde edilen fayda düzeyleri arasında farklılık olmadığını saptamıştır. Katılımcıların haftalık serbest zaman süreleri arttıkça mutluluk 
düzeyleri de artmaktadır. Ancak bu farklılık istatistiksel olarak anlamlı bulunmamıştır. Elde edilen bu bulgular 1şığında Serdar vd., (2018) tarafından yapılan araştırmanın sonuçları ile bu çalışmanın sonuçlarının paralellik gösterdiği anlaşılmaktadır.

Yapılan regresyon analizi sonuçları incelediğinde ise, bireylerin serbest zamandan elde ettikleri fayda düzeylerinin mutluluk düzeylerinin anlamlı bir yordayıcısı olduğu ve bireylerin serbest zaman fayda düzeyleri ile mutluluk düzeyleri arasında pozitif yönde ve düşük düzeyde bir ilişki olduğu saptanmıştır. Bireylerin serbest zamandan elde ettikleri faydalar arttıkça mutluluk düzeyleri de artmaktadır. Bu çalışmanın sonuçları ile Chen vd., (2013), Doğan (2018) ve Yalçınkaya (2019) tarafından yapılan çalışmalarının sonuçları paralellik göstermektedir.

\section{Sonuç}

Erkeklerin kadınlara oranla mutluluk düzeylerinin daha yüksek olduğu ve serbest zamanlardan fiziksel ve psikolojik yönden daha fazla fayda elde ettikleri belirlenmiştir. Refah durumu iyi olan bireylerin mutluluk düzeylerinin daha yüksek olduğu anlaşılmıştır. Ancak bireylerin refah durumlarının serbest zamandan elde ettikleri fayda düzeyleri üzerinde etkili olmadığ1 gözlenmiştir. Bireylerin serbest zaman süreleri arttıkça mutluluk düzeylerinin de arttığı ve serbest zamandan daha çok sosyal yönden fayda elde ettikleri anlaşılmıştır. Bireylerin serbest zamandan elde ettikleri faydaların mutlulukları üzerinde önemli bir etkiye sahip olduğu sonucuna varılmıştır. Ulusal alanyazında serbest zamandan elde edilen fayda düzeyleri ile mutluluk düzeyleri arasındaki ilişkileri inceleyen çalışmaların sınırlı sayıda olması nedeniyle bu konuda yapılacak araştırmaların sayıları arttırılmalıdır. Özellikle bundan sonra yapılacak olan çalışmalarda örneklem grubu olarak çeşitli meslek grupları, farklı fakültelerde öğrenim gören öğrenciler ile toplumun her kesimini kapsayacak şekilde ele alınması ve elde edilen sonuçların karşılaştırılmasının ulusal ve uluslararası literatüre önemli katkı sağlayacağı düşünülmektedir.

\section{Kaynakça}

Akgül, B.M., Ertüzün, E. \& Karaküçük, S. (2018). Leisure benefit scale: a study of validity and reliability. Gazi Beden Eğitimi ve Spor Bilimleri Dergisi, 23(1), 25-34.

Akyüz, H., Yaşartürk, F., Karataş, İ., Türkmen, M. \& Zorba, E. (2018). Rekreasyon bölümünde öğrenim gören öğrencilerin serbest zaman motivasyonlarının mutluluk düzeyi üzerine etkisi. Journal of Human Sciences, 15(2), 1086-1096.

Arvas, F.B. (2017). Psikolojide ve islam düşünce geleneğinde mutluluk kavramı: karşılaştırmalı bir çalışma. İnsan ve Toplum Bilimleri Araştırmaları Dergisi, 6(4), 109-128.

Aydın, İ. (2016). Fitness katılımcılarının rekreasyonel etkinliklere yönelik ilgilenim ve mutluluk düzeylerinin belirlenmesi. Gazi Üniversitesi Sağlık Bilimleri Enstitüsü.

Bright, A.D. (2000). The role of social marketing in leisure and leisure activities management. Journal of Leisure Research, 32(1), 12-18.

Camfield, L. \& Skevington, S.M. (2008). On subjective well-being and quality of life. Journal of Health Psychology, 13(6), 764-775.

Chang, Y.C., Yeh, T.M., Pai, F.Y. \& Huang, T.P. (2018). Sport activity for health!! The effects of karate participants' involvement, perceived value, and leisure benefits on recommendation intention. International Journal of Environmental Research and Public Health,15(953), 116. 
Chen, C.C., Cheng, C.H. \& Lin, S.Y. (2013). The Relationship among leisure involvement, leisure benefits, and happiness of elementary schoolteachers in Tainan country. International Research in Education, 1(1), 29-51.

Coleman, D. (1993). Leisure based social support, Leisure dispositions and health. Journal of Leisure Research, 25(4), 350-361.

Demirel, M. (2019). Leisure involvement and happiness levels of individuals having fitness center membership. Journal of Education and Learning, 8(6), 140-149.

Dikici, İ. (2020). Serbest zamanları gençlik merkezlerinde değerlendiren üniversite ögrencilerinin serbest zaman doyum, yaşam doyumu ve mutluluk düzeylerinin incelenmesi. Muğla Sitk1 Koçman Üniversitesi, Sosyal Bilimler Enstitüsü.

Doğan, M., Elçi, G. \& Gürbüz, B. (2019). Serbest zaman doyumu, serbest zamanda sıkılma algısı ve iş tatmini ilişkisi: Akademisyenler üzerine bir araştırma. SPORMETRE Beden Eğitimi ve Spor Bilimleri Dergisi, 17(1), 154-164.

Doğan, M.N. (2018). Hukuk fakültesi ögrencilerinin rekreasyonel aktivitelerden elde ettikleri faydaların mutluluk düzeylerinin incelenmesi. Gazi Üniversitesi Sağlık Bilimleri Enstitüsü.

Doğan, T. \& Çötok, N.A. (2011). Oxford mutluluk ölçeği kısa formunun türkçe uyarlaması geçerlik ve güvenirlik çalışması. Türk Psikolojik Danışma ve Rehberlik Dergisi, 4(36), 165-172.

Durmaz, H. (2020). Gençlerin serbest zaman etkinliklerine yönelik tutumlart ile doyum ve mutluluk düzeyleri arasındaki ilişki: manisa gençlik merkezleri örneği. Manisa Celal Bayar Üniversitesi, Sosyal Bilimler Enstitüsü.

Eccles, J.S. (2005). Studying the development of learning and task motivation. Learning and Instruction, 15(2), 161-171.

Eskiler, E., Yıldiz, Y. \& Ayhan, C. (2019). The effect of leisure benefits on leisure satisfaction: Extreme sports. Turkish Journal of Sport and Exercise, 21(1), 16-20.

Gümüşgül, O. (2019). Sports or fine arts? Investigation of free time management skills of participants interested in sports and fine arts. Journal Educational Issues, 5(1), 20- 29.

Güngörmüş, H.A., Beşikçi, T., Gürbüz, B. \& Sarol, H. (2017). The relationship between leisure satisfaction and psychological well-being: A research about Turkish adults. World Congress of Sport Sciences Research, 223- 224, 23-26 November, Manisa, Turkey.

Gürbüz, B. (2017). The conception and perception of leisure in Turkey. In K. Henderson, \& A. Sivan (Eds), Leisure from International Voices, Champaign, IL: Sagamore Publishing.

Henderson, K. (2010). Leisure studies in the 21St century: The Sky is Falling?. Leisure Sciences. 32(4), 391-400.

Hills, P. \& Argyle, M. (2002). The oxford happiness questionnaire: a compact scale for the measurement of psychological well-being. Personality and Individual Differences, 33, 1073-1082.

Ho, T.K. (2008). A study of leisure attitudes and benefits for senior high school students at pingtung city and country in Taiwan (Unpublished Doctoral Dissertation). United States Sports Academy, Daphne, AL.

Huang, C.E., Tsai, C.Y. \& Lee, S.C. (2014). A study of the influence of college students' exercise and leisure motivations on the leisure benefits-using leisure involvement as a moderator. International Journal of Humanities and Social Sciences. 8(8), 2427-2431. 
Hung, H.J. (2012). A study on leisure benefits breaking through leisure activities. Journal of National Taiwan Normal University, 3(4), 77-92.

İslamoğlu, A.H. \& Alnıç̧ı, Ü. (2014). Sosyal Bilimlerde Araştırma Yöntemleri. (4. Baskı): Beta Basım Yayım Dağıtım A.Ş.

Karaca, A.A. \& Lapa, T.Y. (2016). Serbest zaman katılımı, psikolojik iyi olma ve serbest zaman engelleri ile baş etme stratejilerinin üniversite öğrencileri üzerinde incelenmesi. Journal of Human Sciences, 13(2), 3293-3304.

Karasar, N. (2014). Bilimsel Araştırma Yöntemi. 27 Basım. Nobel yayıncılık.

Kaya, S. (2016). The relationship between leisure satisfaction and happiness among College students. Universal Journal of Educational Research, 4(3), 622-631.

Kim, J., Heo, J., Dvorak, R., Ryu, J. \& Han, A. (2018). Benefits of leisure activities for health and life satisfaction among western migrants. Annals of Leisure Research, 21(1), 47-57.

Kocaer, G. (2018). Beden eğitimi ve spor ögretmenleri ve adaylarının ögretmenlik mesleğine yönelik tutum, serbest zaman ilgilenim ve rekreasyon faaliyetlerine yönelik fayda düzeyleri arasındaki ilişskinin incelenmesi (Bartın ili örneği). Bartın Üniversitesi, Eğitim Bilimleri Enstitüsü.

Kuo, C.T. (2013). A study of the correlation between leisure benefits and behavioral intentions-using bantou arts and cultural village as an example. International Review of Management and Business Research. 2(4), 1065-1074.

Lee, C.J., Tseng, C.C. \& Liu, M.Y. (2016). Study on community Tai Chi Chuan participants leisure benefits and well-being: using taoyuan city as an example. Technology and Health Care. 24, 289-295.

Lee, Y.D. \& Lin, L.H. (2011). Leisure motivation and life satisfaction: Test of mediating effect of leisure benefit. Journal of Information and Optimization Sciences. 32(3), 749-761.

Liu, H. \& Da, S. (2020). The relationships between leisure and happiness-A graphic elicitation method. Leisure Studies. 39(1), 111-130.

Sapmaz, F. \& Doğan, T. (2012). Mutluluk ve yaşam doyumunun yordayıcısı olarak iyimserlik. Mersin Üniversitesi Eğitim Fakültesi Dergisi. 8(3), 63-69.

Sarol, H., Aydın, İ., Gümüşboğa, İ., Güngörmüş, H.A. \& Alıcı, Y. (2020). Otizmli çocuğa sahip ebeveyn perspektifi ile serbest zaman ve fiziksel aktivitenin anlam1. SPORMETRE Beden Eğitimi ve Spor Bilimleri Dergisi, 18(1), 144-155.

Serdar, E., Demirel, M., Demirel, D.H. \& Donuk, B. (2018). Üniversite öğrencilerinin serbest zaman doyum düzeyleri ile mutluluk düzeyleri arasındaki ilişki. Sosyal Bilimler Dergisi. 5(28), 429438.

Sevin, H.D. \& Şen, K. (2019). Öğretmenlerin rekreasyon aktivitelerine katılım düzeyleri ile yaşam mutluluğu ve iş performansları arasındaki ilişki. Dini Araştırmalar Dergisi. 22(55), 213-232.

Spiers, A. \& Walker, G.J. (2008). The effects of ethnicity and leisure satisfaction on happiness, peacefulness, and quality of life. Leisure Sciences. 31(1), 84-99.

Tinsley, H.E.A. \& Tinsley, D.J. (1986). A theory of the attributes, benefits, and causes of leisure experience. Leisure Sciences. 8(1), 1-45.

Wei, X., Huang, S.S., Stodolska, M. \& Yu, Y. (2015) Leisure time, leisure activities, and happiness in China. Journal of Leisure Research. 47(5), 556-576. 
Yalçınkaya, N. (2019). Üniversite ögrencilerinin rekreasyon fayda algıları ile mutluluk düzeyleri arasındaki ilişkinin belirlenmesi. Sakarya Uygulamalı Bilimler Üniversitesi Lisansüstü Eğitim Enstitüsü.

Yeh, T.M. Chang, Y.C. \& Lai, M.Y. (2017). The relationships among leisure experience, leisure benefits and leisure satisfaction of you bike users. J. Sport Leis. Hosp. Res. 12, 67-97.

Yurcu, G., Kasalak, M.A. \& Akıncı, Z. (2018). Turistlerin boş zaman motivasyonu ve tatminini etkileyen faktörler: Beldibi örneği. MANAS Journal of Social Studies. 7(2), 518-536. 